\title{
Clinical study of pneumonia with wheeze in children
}

\author{
Pandwar $\mathbf{U}^{1}$ \\ ${ }^{1}$ Dr. Umesh Pandwar, Assistant Professor, Department of Pediatrics, Gandhi Medical College, Bhopal, MP, India.
}

Address for Correspondence: Dr. Umesh Pandwar, E-mail: umeshpandwar@gmail.com

\begin{abstract}
Introduction: In developing world, important reason for morbidity and mortality in children are acute respiratory tract infections. Annually about 3.8 million children die because of acute respiratory illnesses mostly in developing world. Pneumonia is often associated with wheeze in significant number of cases. Objective: The study was aimed to assess the clinical and epidemiological profile of admitted patients with diagnosis of Pneumonia in department of paediatrics with or without wheeze on the basis of age and sex. Methods: A retrospective observational study in Department of paediatrics, Gandhi Medical College and associated Hospital from May 2013 to May 2015. Children admitted in department of paediatrics aged up to 12 years with clinical manifestations suggestive of pneumonia were included (fever, cough, rapid breathing, crepitation and wheeze). Patients with history of Tuberculosis, Asthma and associated cardiac problems were excluded. Outcome was assessed on the basis of magnitude of problem and morbidity. Results: A total of two thousand eight hundred and forty seven children with diagnosis of pneumonia were admitted and out of them seven hundred and sixty seven (27\%) children had wheeze. Most of the children having pneumonia with wheeze come under the age group of 2 to 12 months. Male children are affected more than female children. Conclusion: In significant number of children, pneumonia is associated with wheeze, especially in the age group of 2-12 months. It is also common in children with age group of 1-5 yrs. Therefore, pneumonia is a significant cause of morbidity in children. Morbidity may further increase when pneumonia is associated with wheeze.
\end{abstract}

Key words: Pneumonia, Wheeze, Pneumonia, Children

\section{Introduction}

In children below the age of 5 years, Acute respiratory tract infection is an important cause of morbidity and mortality, especially in underdeveloped nations. It has been found that approximately 4 million children loss their live annually due to acute respiratory tract infections mostly in under-developed nations [1].

In underdeveloped nations, about $15-25 \%$ children with the age of less 5 years suffered from Pneumonia every year. Often wheeze is associated with pneumonia in these children. It has been found that in about $34 \%$ of children suffered from pneumonia, wheeze was an associated finding [2]. Smaller age (2-4 months), poor status of education in parents, parental smoking, history of premature birth, premature discontinuation of exclusive breast

Manuscript received: $6^{\text {th }}$ October 2017

Reviewed: $17^{\text {th }}$ October 2017

Author Corrected: $25^{\text {th }}$ October 2017

Accepted for Publication: $30^{\text {th }}$ October 2017 feeding before 6 months or history of top feed before 6 months of age, history of inappropriate vaccination particularly against Pertussis and Diphtheria, poor nutritional status, Anemia and other vitamins deficiency especially deficiency of vitamin A are the significant risk factors responsible for Pneumonia [3].

In children wheeze may be caused by respiratory infections which can also be held responsible for acute exacerbations of asthma. Now it has become well known that infections by Mycoplasma and Chlamydia which are pathogens of intracellular in nature, are responsible in some patients for wheeze whether it is acute or chronic [4]. ARI are more important than realized previously and almost certainly are the leading cause of death in children in developing countries [5]. This study's objective was to measure the percentage of children having pneumonia associated with wheeze out of all 
admitted children having diagnosis of pneumonia. Objective was also to assess the difference in rates of association of wheeze with pneumonia in different age groups and different sex among children admitted with diagnosis of pneumonia.

\section{Methodology}

Type of study: This was a retrospective observational study. Place of study: It was conducted at department of Pediatrics, Kamla Nehru Hospital, Gandhi Medical College, Bhopal, MP. Duration of study was period of 2 years starting from May 2013-May 2015.

Inclusion criteria: All children who came with clinical feature suggestive of pneumonia such as fever, cough, fast breathing were included. Clinical examination findings such as crepitation and wheeze in these children were noted down.

Exclusion criteria: Patients who had associated diagnosis or history of Tuberculosis, Bronchial asthma, Congenital heart disease, congenital respiratory tract anomalies and chest wall abnormalities were excluded.

Sample collection: From all those children who were included in this study, data were collected from the hospital record of paediatrics department.

All the collected data were properly analysed and given tabulated form.

\section{Results}

This study's objective was to measure the percentage of children having pneumonia associated with wheeze out of all admitted children having diagnosis of pneumonia. Objective was also to assess the difference in rates of association of wheeze with pneumonia in different age groups and different sex among children admitted with diagnosis of pneumonia.

A total of Two thousand eight hundred and forty seven children with the diagnosis of Pneumonia were there, out of whom sixteen hundred and twenty three children were male and twelve hundred and twenty four children were female. There were seven hundred and sixty seven children (27\%) among patient with Pneumonia who had wheeze and remaining two thousands and eighty children $(73 \%)$ who did not have wheeze. Most of them were found to be in $2-12$ months of age groups.

The results of study are as given below.

Table 1: Distribution of subjects.

\begin{tabular}{|c|c|c|c|}
\hline & Male & Female & Total \\
\hline Pneumonia with wheeze & 468 & 299 & 767 \\
\hline $\begin{array}{c}\text { Pneumonia without } \\
\text { wheeze }\end{array}$ & 1155 & 925 & 2080 \\
\hline Total & $\mathbf{1 6 2 3}$ & $\mathbf{1 2 2 4}$ & $\mathbf{2 8 4 7}$ \\
\hline
\end{tabular}

Table-2: Distribution of cases according to age groups.

\begin{tabular}{|c|c|}
\hline Children's age & No of cases of pneumonia with wheeze \\
\hline $1-2$ months & $31(4.0 \%)$ \\
\hline 2 month-1year & $534(69.6 \%)$ \\
\hline 1year-5year & $192(25.0 \%)$ \\
\hline More than 5year & $10(1.3 \%)$ \\
\hline
\end{tabular}

\section{Discussion}

Infectious illness related to respiratory tract such as Bronchiolitis, Pneumonia etc. are predominant cause of morbidity and mortality among children especially in underdeveloped nations of the world. Children in many nations which belong to the group of third world countries in African and Asian 
continents are having many times more incidence and prevalence of respiratory tract illness of infectious in origin as compared to those in the developed countries [6].

When there was no availability of vaccines, the bacterial pneumonia was mainly caused by Streptococcus pneumoniae and Haemophillus influenzae, while in some cases of severe pneumonia, Staphylococcus aureus and Klebsiella pneumonae were responsible [7].

A study done by Rudan et al shows that there are differences in term of etilogical agents responsible for pneumonia on the basis of its severity. In term of overall incident in a community, the most common organism is Respiratory syncytial virus, which were there in almost $28.8 \%$ of all cases, which is followed by influenza (17.0\%), while Sterptococcus Pneumonae was responsible for only $6.9 \%$ of patients and $\mathrm{Hib}$ were there in only $2.8 \%$ of patients. When we come to the severe pneumonia, RSV pneumonia incidence declined to $22.6 \%$ and influenza incidence decreased to $7.0 \%$, whereas incidence of Sterptococcus Pneumonae increased to $18.3 \%$ and $\mathrm{Hib}$ increased to $4.1 \%$ [8].

In case of children with pneumonia, the information about the organism which is responsible is not known most of the time at the start of treatment and therefore the choice of antimicrobial has to be decided by the prevalence of different organisms at different ages groups, information about resistance of microbes within the area and the status of immunisation [9].

Different antimicrobials have been found to have similar effectiveness against common organisms pevelant in the area e.g. Macrolides such as Azithromycin, Erythromycin, Amoxicillin and Amoxicillin plus Clavulanate, Cephalosporins such as cephalaxin, cefpodoxime, cefuroxime, ceftriaxone and cefotaxime [10].

Since few decades role of acute respiratory illness as a leading cause of deaths have become smaller. These changes probably may be linked to widespread use of antibiotics in a large scale. As in developed nations similar pattern of contribution of acute respiratory illnesses in morbidity and mortality among children has been observed [11]. Age wise predilection of respiratory tract illness in children is very obvious. Mortality due to acute respiratory infections is most marked in neonatal age group and decline as age advances.

As compared to other causes, acute respiratory infections are the leading cause of mortality in the children beyond neonatal age group. Among acute respiratory infections, pneumonia is responsible for major proportion of deaths in children belong to underdeveloped nations. Many vaccine preventable diseases such as pertussis and measles have significant complications in the form of acute respiratory illnesses and Pneumonia. Many other infectious agents also frequently involve respiratory tract. Severe malnutrition also predisposes children to acute respiratory infections and can also be responsible for increased severity of these illnesses.

To determine the role of acute respiratory infections as a cause of mortality in children belong to lesser than 5 years of age group there is scarcity of data in underdeveloped nations. WHO estimated that acute respiratory infections and/or associated illnesses accounts for 1 in 3 deaths among children belong to under5 years of age groups in underdeveloped nations. To a large extent, this estimate may be considered close to the real scenario about contribution of acute respiratory infections and/or associated illnesses in mortality among children belong to lesser than 5 years of age group in underdeveloped nations[12].

Children with pneumonia constituted almost $25 \%$ of all admitted cases in paediatrics as shown in our study. Identical findings were observed in a systemic analysis with the title of Global, regional, and national causes of child mortality in 2008: a systematic analysis done by Bryce $\mathrm{J}$ et al and Black $\mathrm{RE}$ et al. There were about $32 \%$ children admitted because of pneumonia among pediatric population as shown in this study [13].

In this study, male children constituted about $57 \%$ as against female children who were $43 \%$ among all children admitted with Pneumonia. Similarly, there were $55 \%$ male children and $43 \%$ female children among all children with pneumonia as found in the study done by Farha $\mathrm{T}$ et al in their study [14]. Identical with the above finding more number of male children were there among children with pneumonia as compared to female children as shown by Adam KA et al in his study [15]. 
There were about $27 \%$ of children had wheeze among all children admitted with pneumonia as shown in this study. Similar observations were made in the study done by Nascimento-Carvalho CM et al. There were about $23 \%$ children has been shown to have wheeze among all children affected with pneumonia [16]. Nystad W et al found $40 \%$ wheezing among Pneumonia Patients [17]. As shown in this study, the age group which is common for pneumonia is 2 months to 12 months of age. Pneumonia is also found to be most prevalent among infants as shown in a study done by Mitra NK et al [18].

\section{Conclusion}

As shown in this study, pneumonia is a disease which puts significant burden on health care system, which may be the reason that make it responsible for an important cause of morbidity and mortality among children. Viruses are responsible for most of the cases of pneumonia in children and are commonly found in children. The most common bacteria responsible for pneumonia in children is Streptococcas pneumoniae. Attempts to identify the causative organism should be made in cases of severe pneumonia. Antibiotics should be given to every case of definite clinical diagnosis of as it is not possible to distinguish pneumonia of viral origin from that of pneumonia of bacterial origin on the basis of clinical signs and other initial investigations such as acute phase reactants. It can be concluded that wheeze is an important clinical sign of pneumonia. The association of wheeze with pneumonia may makes the course of disease more prolonged and complicated, which in turn may contribute to increase morbidity and mortality among children.

What this study adds: Wheeze can be considered as an important sign of pneumonia in children.

Contributor: UP: Data collection, interpretation and tabulation, manuscript writing.

Funding: Nil, Conflict of interest: None initiated, Perission from IRB: Yes

\section{References}

1. Bryce J, Boschi-Pinto C, Shibuya K, Black RE; WHOChild Health Epidemiology Reference Group. WHO estimates of the causes of death in children. Lancet. 2005 Mar 26-Apr 1;365(9465):1147-52.
2. Martinez FD, Wright AL, Taussig LM, Holberg CJ, Halonen M, Morgan WJ. Asthma and wheezing in the firstsixyearsoflife. The Group Health Medical Associates. N Engl J Med.1995 Jan19; 332 (3): 133-8.

3. Shah N, Ramankutty V, Premila PG, Sathy N. Risk factors for severe pneumonia in children in south Kerala: a hospital-based case-control study. Journal of tropical pediatrics. 1994 Aug 1; 40 (4): 201-6.

4. McIntosh K, Ellis EF, Hoffman LS, Lybass TG, Eller JJ, Fulginiti VA. The association of viral and bacterial respiratory infections with exacerbations of wheezing in young asthmatic children.The Journal of pediatrics. 1973 Apr 30;82(4):578-90.

5. Berman S, McIntosh K. Selective primary health care: strategies for control of disease in the developing world. XXI.Acute respiratory infections. Review of Infectious Diseases. 1985 Sep 1;7 (5): 674-91.

6. Chretien J, Holland W, Macklem P, Murray J, Woolcock A. Acute respiratory infections in children: a global public-health problem. New England Journal of Medicine. 1984 Apr 12; 310 (15): 982-4.

7. Shann F. Etiology of severe pneumonia in children in developing countries. The Pediatric Infectious Disease Journal. 1986 Mar 1; 5 (2): 247-52.

8. Rudan I, O'Brien KL, Nair H, Liu L, Theodoratou E, Qazi S, Lukšić I, Fischer Walker CL, Black RE, Campbell H; Child Health Epidemiology Reference Group (CHERG). Epidemiology and etiology of childhood pneumonia in 2010: estimatesofincidence, severemorbidity, mortality, underlyingrisk factors and causativepathogens for 192countries.J Glob Health. 2013 Jun; 3(1): 010401. doi: 10. 7189/ jogh. 03. 010401 .

9. Harris M, Clark J, Coote N, Fletcher P, Harnden A, McKean M, Thomson A; British Thoracic Society Standards of Care Committee. British Thoracic Society guidelines for the management of community acquired pneumonia in children: update 2011. Thorax. 2011 Oct;66 Suppl 2:ii1-23. doi: 10. 1136/thoraxjnl-2011-200598. 
10. WubbelL, Muniz L, Ahmed A, Trujillo M, Carubelli C, McCoig C, Abramo T, Leinonen M, Mc Cracken GH Jr.Etiology and treatment of community-acquiredpneumonia in ambulatory children. Pediatr Infect Dis J.1999Feb;18(2):98-104.

11. Leowski J. [Mortality from acute respiratory infections in children under 5 years of age: global estimates]. World health statistics quarterly.1986 Oct 4;39(2):138-44.

12. Rudan I, Boschi-Pinto C, Biloglav Z, Mulholland K, Campbell H. Epidemiology and etiology of childhood pneumonia. Bulletin of the WorldHealthOrganization.2008May;86(5):408-16B.

13. Black RE, Cousens S, Johnson HL, Lawn JE, Rudan I, Bassani DG, Jha P, Campbell H, Walker CF, Cibulskis R, Eisele T, Liu L, Mathers C; Child Health Epidemiology Reference Group of WHO and UNICEF. Global, regional, and nationalcauses of child mortality in 2008: a systematicanalysis. Lancet. 2010 Jun 5;375(9730):1969-87. doi: 10. 1016/ S0140-6736(10)60549-1. Epub 2010 May 11.
14. Farha T, Thomson AH. The burden of pneumonia in children in the developed world. Paediatr Respir Rev. 2005 Jun;6(2):76-82.

15. Adam KA. Persistent or recurrent pneumonia in Saudi children seen at King Khalid University Hospital, Riyadh: clinical profile and some predisposing factors. Annals of tropical paediatrics. 1990 Dec;11(2):129-35.

16. Nascimento-Carvalho CM, Rocha $\mathrm{H}$, Benguigui Y. Association of crackles and/or wheezing with tachypnea or chest indrawing in children with pneumonia. Indian pediatrics. 2002 Feb 28;39 (2): 205-6.

17. Nystad W, Nafstad P, Jaakkola JJ. The effect of respiratory tract infections on reported asthma symptoms. Scand J Public Health. 2002;30(1):70-5.

18. Mitra NK. A longitudinal study on ARI among rural under fives. Indian Journal of community medicine. 2001 Jan 1;26(1):8-11.

\section{How to cite this article?}

Pandwar U. Clinical study of pneumonia with wheeze in children. Int J Pediatr Res. 2017;4(10):629-633.doi:10. 17511/ijpr.2017.i10.08. 